\title{
A SUINOCULTURA NO OESTE CATARINENSE E AS COMPLEXAS IMPLICAÇÕES AMBIENTAIS
}

\section{THE PIG INDUSTRY IN THE WESTERN REGION OF THE STATE OF SANTA CATARINA AND THE COMPLEX ENVIRONMENTAL IMPLICATIONS}

\author{
Jairo Marchesan ${ }^{1}$ \\ Angelo Martins Fraga ${ }^{2}$
}

\section{Resumo}

A Região Oeste do Estado de Santa Catarina destaca-se como uma das maiores produtoras de suínos do Brasil. Exporta para diversos países e concentra as maiores agroindústrias do País. Aproximadamente 28 mil suinocultores são integrados às agroindústrias localizadas na região. A suinocultura é uma das atividades agropecuárias que causa grande pressão sobre os recursos naturais e gera enorme impacto ambiental no solo, ar e águas em função do volume de dejetos produzido. A problemática agravase pela crescente concentração de animais nos estabelecimentos agrícolas em determinada área geográfica, decorrente da lógica produtivista capitalista, que exige redução de custos de produção e maior produtividade a qualquer custo. Com a crescente preocupação ambiental na década de 1990, firmou-se em 2003 o Termo de Compromisso de Ajustamento de Condutas (TAC) da Suinocultura. Entre os objetivos está a melhoria da qualidade ambiental nas bacias hidrográficas dos rios mais atingidos no estado, através da adequação das atividades da suinocultura, em especial pela adoção de gestão tecnológica e práticas de manejo ambientalmente adequadas aplicáveis em microbacias. Este ensaio busca refletir sobre a história da produção agropecuária e as complexas implicações ambientais decorrentes desse processo.

Palavras-chave: suinocultura; agroindústria; produção; integrados; meio ambiente.

\begin{abstract}
The western region of the state of Santa Catarina stands out as one of the largest pig producers in Brazil. It exports to several countries and concentrates the largest agribusinesses in the country. Approximately 28.000 pig farmers are integrated to the agribusiness located in the region. The swine production is one of the agricultural activities that cause great pressure on natural resources and generates enormous environmental impact on soil, air and water because of the volume of waste that is produced. The problem is aggravated by the concentration of farm animals in certain geographical areas, as a result of the capitalist productivist logic that demands reduction of production costs and higher productivity at any cost. Because of the growing environmental concern in the 1990s, the Swine Conduct Adjustment Agreement (TAC)
\end{abstract}

\footnotetext{
${ }^{1}$ Doutor em Geografia (UFSC, 2007). Professor Efetivo de Geografia do Ensino Médio da Rede Estadual de Educação de Santa Catarina. Professor da Graduação e Programa de Pós-Graduação - Mestrado em Desenvolvimento Regional da Universidade do Contestado (jairo@netcon.com.br). Autor para correspondência. Rua Santa Catarina, 257 - Concórdia - SC - CEP 89700-000.

${ }^{2}$ Mestre em Geografia (UFSC, 2013). Professor do Curso Técnico de Agrimensura do Instituto Federal de Ciência e Tecnologia de Santa Catarina (IFSC), Campus Florianópolis (angelofraga@yahoo.com.br).
} 
was signed in 2003. Among its objectives is to improve environmental quality in the basins of the most affected rivers in the state through the adequacy of the activities of the swine farms, in particular the adoption of technology management and environmentally sound management practices applicable in watersheds. This essay seeks to reflect on the history of agricultural production and the complex environmental implications that result from this process.

Keywords: swine, agribusiness, production, integrated, environment.

\section{1 - INTRODUÇÃO}

Abrigando um plantel com mais de 34 milhões de suínos, o Brasil é um dos maiores produtores mundiais desse setor alimentício. São abatidos mensalmente mais de dois milhões de cabeças. Os maiores produtores nacionais são os estados da região sul do país. Santa Catarina, Paraná e Rio Grande do Sul possuíam, em 2005, respectivamente, 6,3; 4,5 e 4,2 milhões de cabeças (BRASIL, 2010).

A suinocultura foi uma atividade econômica desenvolvida, fundamentalmente, em pequenas propriedades rurais. O Estado de Santa Catarina conta com 80 mil suinocultores, $80 \%$ dos quais se situam na mesorregião oeste, em propriedades com a área média de 16 hectares. Em torno de 28 mil produtores são integrados às agroindústrias localizadas nessa área. A produção caracteriza-se pela sua forte orientação ao mercado internacional (GUIVANT, 1998).

Porém, a suinocultura, simultaneamente, é uma das atividades econômicas de maior impacto ambiental em função do grande volume de dejetos produzido. $\mathrm{O}$ desempenho econômico ocorreu concomitante à grande pressão sobre os recursos naturais, como a poluição do ar, da água e dos solos. Isso se agrava pela crescente concentração de produção sobre determinada área geográfica e a grande lotação de animais nos estabelecimentos suinícolas, decorrentes da tecnificação e da constante busca por redução de custos de logística. Portanto, os problemas ambientais são provocados pelo aumento do rebanho, concentração da produção animal e intenso processo de despejo de dejetos suínos nas lavouras, que, gradativamente, são carreados para os rios. Entre 1985 e 1998, técnicos de Santa Catarina realizaram 18.000 exames bacteriológicos de água para o consumo de famílias rurais, abrangendo todo o estado. Os resultados foram impressionantes: de cada dez amostras examinadas, oito, em média, apresentaram contaminação bacteriológica (BEZERRA; VEIGA, 2000). 
Para ter-se uma ideia do problema, cada matriz, em uma granja de suínos de ciclo completo, produz até $25 \mathrm{~m}^{3}$ de dejetos ao ano, que se compõem de esterco, urina, desperdícios de água de bebedouros ou de limpeza, entre outros (OLIVEIRA, 1994).

Com a crescente preocupação ambiental inerente à década de 1990, foi firmado, em 2003, o Termo de compromisso de Ajustamento de Condutas (TAC) da suinocultura, visando melhorar a qualidade ambiental nas bacias hidrográficas dos rios mais atingidos no Estado.

Diante disso, este ensaio busca refletir brevemente sobre o processo histórico da produção agropecuária, especialmente suinícola, no Oeste Catarinense e suas implicações ambientais e na qualidade de vida das pessoas e do ambiente.

\section{2 - A SUINOCULTURA NO OESTE CATARINENSE}

Geograficamente, denomina-se de Mesorregião Oeste Catarinense o território que se localiza no Oeste do Estado de Santa Catarina e que se limita: ao Sul, com o Estado do Rio Grande do Sul; ao Norte, com o Estado do Paraná; a Oeste, com a República Argentina e, ao Leste, com o Planalto Catarinense. O IBGE denomina essa região de Mesorregião Oeste Catarinense, composta pelas microrregiões Colonial e Oeste Catarinense. Essa Mesorregião ${ }^{3}$ possui uma dimensão de $27.365 \mathrm{~km}^{2}$ (Figura 1) e conta com aproximadamente um milhão e 200 mil habitantes.

\footnotetext{
${ }^{3}$ A Mesorregião Oeste Catarinense baseia-se nas delimitações político-administrativas estabelecidas pelo IBGE e, também, na sua formação e identificação histórico-cultural e socioeconômica.
} 


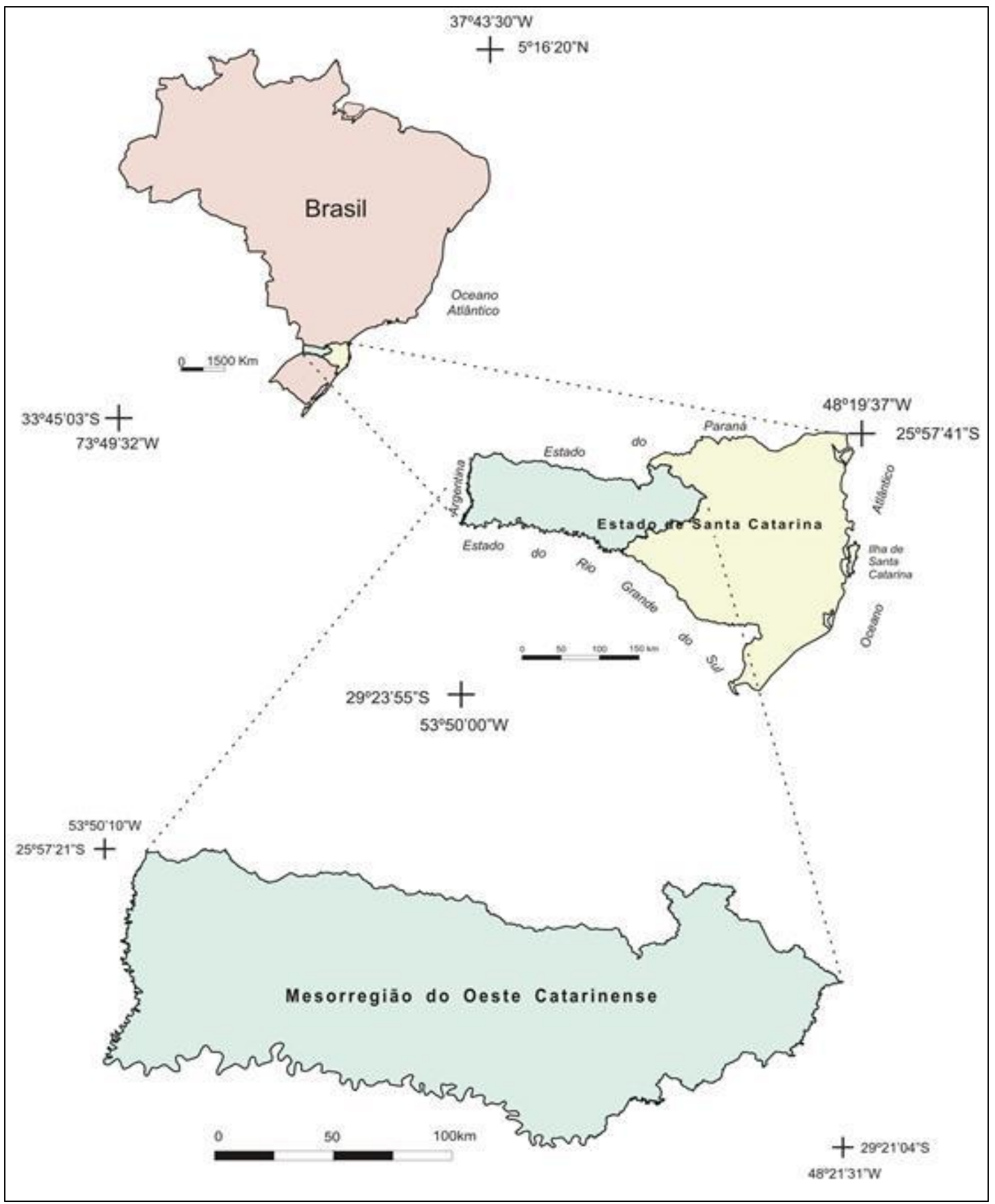

Figura 1: Mapa de Localização da Mesorregião Oeste Catarinense Fonte: IBGE (2006).

O Oeste Catarinense detém $81,7 \%$ do total da produção de suínos do estado. Nessa área, estão localizadas as maiores agroindústrias que atuam no setor (EPAGRI/EMBRAPA, 2000). Ainda, detém atualmente o maior complexo agroindustrial de suínos e aves do Brasil. Em Santa Catarina, o abate total cresceu em torno de $220 \%$, no período de 1975 a 1996, e com evolução que pode ser visualizada na 
Tabela 1. Percebe-se que a participação percentual sobre o abate nacional cresceu constantemente no período, com 16,3\% em 1975, 29,6\% em 1985 e uma década após, em 1995, com 33,4\% de participação (EPAGRI/EMBRAPA, 2000).

Tabela 1: Evolução do abate de suínos em Santa Catarina em relação ao abate no Brasil, entre os anos de 1975 e 1996.

\begin{tabular}{c|c|c|c}
\hline Ano & $\begin{array}{c}\text { Produção } \\
(\mathbf{1 0 0 0} \text { cabeças) }\end{array}$ & $\begin{array}{c}\text { Taxa de abate } \\
(\boldsymbol{\%})\end{array}$ & $\begin{array}{c}\text { Participação no abate } \\
\text { brasileiro }(\boldsymbol{\%})\end{array}$ \\
\hline 1975 & 2145 & 61,2 & 16,3 \\
1980 & 3882 & 99,6 & 21,9 \\
1985 & 4142 & 130,6 & 29,6 \\
1990 & 4552 & 135,9 & 28,4 \\
1995 & 6408 & 171,9 & 33,4 \\
1996 & 6857 & 180,3 & 34,3 \\
\hline
\end{tabular}

Fonte: IBGE; Instituto CEPA/SC; FNP apud EPAGRI/EMBRAPA, 2000.

Na região Oeste Catarinense está estabelecida a Associação dos Municípios do Alto Uruguai Catarinense (AMAUC), em cuja área encontra-se a maior concentração suinícola do estado. Ela representa somente $5 \%$ da área agrícola estadual e detém $22 \%$ do total do efetivo de suínos. Tal situação gera grande produção de dejetos que, de maneira geral, não são adequadamente manejados, ocasionando sérios problemas de poluição dos recursos naturais (EPAGRI/EMBRAPA, 2000).

No ano de 2005, o número de suínos no município de Concórdia era de aproximadamente 300 mil animais, conforme Tabela 2:

Tabela 2: Quantidade de propriedades e de animais criados no município de Concórdia, no ano de 2005.

\begin{tabular}{c|c|c}
\hline Plantel & $\mathbf{N}^{\mathbf{0}}$ de Animais & $\mathbf{N}^{\mathbf{0}}$ de Propriedades \\
\hline Suínos & 300.851 & 987 \\
Aves & 6.012 .000 & 495 \\
Bovinos & 60.789 & - \\
\hline
\end{tabular}

Fonte: IBGE, 2003 (adaptado por Marchesan, 2007a).

Na Tabela 3 a seguir, pode-se visualizar o número de estabelecimentos e o tipo de vínculo com a agroindústria na região do Alto Uruguai Catarinense, conforme Pillon et al. (2003).

Tabela 3: Número de estabelecimentos, por vínculo, na região do Alto Uruguai Catarinense, em 2003.

\begin{tabular}{ccc}
\hline Vínculo & Estabelecimentos & Porcentagem \\
\hline Integrado & 1.883 & $50 \%$ \\
Cooperado & 1.012 & $27 \%$
\end{tabular}


Independente

884

Total Geral

3.739

$23 \%$

Fonte: Pillon et al. (2003).

Conforme se pode observar, metade dos produtores rurais da região estava integrada às agroindústrias no ano de 2003.

\section{3 - A PRODUÇÃO AGROPECUÁRIA E OS IMPACTOS AMBIENTAIS}

O modelo de desenvolvimento agropecuário conduzido pela agroindústria do Oeste Catarinense, com o apoio do Estado, baseou-se na pequena propriedade agrícola familiar, associada à produção de vegetais e, ainda, na criação de suínos e aves. Teve, a partir das décadas de 50/60, a implantação do sistema de "projetos de integração" (MARCHESAN, 2003), uma forma e/ou modalidade de produção trazida dos EUA pelo Ministério da Agricultura do Brasil, a convite do governo norte-americano, via Fundação Rockefeller, que organizava grupos de agropecuaristas e agroindustriais para irem aos EUA visitar e conhecer o sistema de integração desenvolvido com os agricultores e pecuaristas daquele país. Nessas viagens, as agroindústrias enviavam aos EUA seus engenheiros agrônomos e técnicos e, no retorno deles, aqui impantaram tal modelo de integração, como "uma estratégia ousada de cópia e aperfeiçoamento, em Santa Catarina, do modelo agroindustrial norte-americano" (ESPÍNDOLA, 1999). Porém, vale ressaltar que não foi apenas uma simples cópia, mas sim a adoção de um plano estrategicamente pensado e articulado pelo capital norte-americano e, posteriormente, transplantado para a região, sob a forma de um sistema de integração verticalizado (BELATO, 1985).

Esses projetos de integração constituem-se numa relação contratual estabelecida entre as agroindústrias e os produtores. Fica estabelecido que as agroindústrias participam na condição de provedoras, através do fornecimento da alimentação, suprimentos, tecnologias, medicamentos, assistência técnica e, por fim, responsabilizam-se pela compra dos animais. Do outro lado, estão os produtores, que disponibilizam a propriedade, instalações (pocilgas) e mão de obra para o cuidado dos animais até serem vendidos para as agroindústrias. O preço do $\mathrm{kg}$ do produto (suínos e aves) é determinado pelo valor estabelecido no mercado. 
O envolvimento com a atividade econômica agropecuária foi e é para os agricultores uma forma de sobrevivência no espaço rural, porém, profundamente vinculada e dependente do conjunto produtivo do capital agroindustrial. Percebe-se, nesse contexto, que essas relações contratuais, formalmente constituídas através de mecanismos, como os projetos de integração e/ou parcerias, reforçam, de forma sistemática e explícita, a subordinação dos produtores integrados ao capital agroindustrial, pois eles se obrigam a aceitar as condições de adquirir as raças e insumos, receber assistência técnica, acatar outras condições das agroindústrias e, ainda, assumir determinados compromissos quanto à entrega dos produtos. Vale ressaltar, entretanto, que, nessas relações, os produtores não são expropriados completamente dos seus meios de produção, porém são levados a ser cada vez mais dominados e subordinados ao processo produtivo agroindustrial no qual estão inseridos (MARCHESAN, 2007a).

Ao longo da década de 1980, o processo de articulação industrial caracterizouse pela intensificação do processo de integração, aumento da escala de produção agropecuária e crescente redução do número de produtores. Isso implicou a instauração de um intenso processo de seleção e exclusão dos produtores rurais (ASSIS, 2004).

Paralelamente àquele período e contexto, um novo agravante foi introduzido na cadeia produtiva agropecuária - a competitividade e a seletividade dos produtores. Só "sobrevivem" os "mais aptos", que produzem em maior quantidade e com melhor qualidade. Foi naquele período que se introduziram, por exemplo, as "granjas-modelo". Tal política de integração agropecuária foi capaz de eliminar os produtores considerados não competitivos, além de concentrar e elevar as produções e a produtividade. A consequência desse processo foi a exclusão social e econômica de muitos produtores que, gradativamente, foram abandonando o meio rural e, assim, reduzindo o número de propriedades voltadas para tal atividade econômica (MARCHESAN, 2007a).

Testa et al. (1996) dizem que, em 1980, existiam 67.000 suinocultores, dos quais restaram cerca de 20.000 em 1995 com tendência de concentração ainda maior. Ou seja, predomina um número menor de propriedades rurais produzindo animais de forma concentrada e intensiva. Geralmente, em tais propriedades não há mais lavouras agricultáveis, ou seja, não há mais cultivo temporário ou sazonal de produção de grãos e, portanto, não há mais onde lançar a crescente produção de dejetos. 
Consequentemente, houve uma grande poluição dos recursos naturais (MARCHESAN, 2007a).

Esse processo, vinculado a esse modelo econômico de desenvolvimento, convergiu para uma intensa exploração econômica do espaço regional, gerando, consequentemente, a mudança da paisagem, a destruição da maior parte da mata nativa, a degradação dos solos e, principalmente, a poluição e carência das águas superficiais. Por isso, pode-se dizer que os problemas ambientais do Oeste Catarinense são consequência de um processo produtivo com base nas atividades econômicas do extrativismo vegetal, cultivo agrícola intensivo e da enorme produção intensiva de animais confinados, principalmente suínos (MARCHESAN, 2007a).

\section{4 - IMPACTO E PASSIVO AMBIENTAL}

Os dejetos suínos são resíduos altamente poluidores do meio ambiente, implicando negativamente na qualidade da água e no desenvolvimento de peixes e outros componentes da fauna e da flora aquáticas. São considerados 100 vezes mais poluentes que o esgoto urbano e representam, de maneira geral, um grande problema ambiental (DAGA et al., 2007). Pesquisas realizadas entre 1990 e 1995, no Oeste de Santa Catarina, pelo Instituto Biológico de São Paulo e divulgados pela Gazeta Mercantil, constataram que as pocilgas da região produziam 8,8 milhões de $\mathrm{m}^{3}$ de esterco por ano - potencial poluidor equivalente ao de uma cidade de 30 milhões de pessoas, gerando a poluição de muitos mananciais (Jornal Gazeta Mercantil, 27 e 28/02 e 01/03/1999).

Guivant \& Miranda (2004), ao discutirem a dimensão da problemática ambiental decorrente da suinocultura no Oeste Catarinense, reproduzem a informação contida na "Revista Expressão" de dezembro de 1993, com a seguinte comparação: Estima-se que com uma população de três milhões de cabeças de suínos, $85 \%$ do rebanho do estado, constitua "a maior concentração deste tipo no mundo, pois produz 24 milhões de metros cúbicos de dejetos por ano. Isso corresponde a um valor imaginário de 24 metros de largura e um metro de altura, de São Miguel do Oeste até Florianópolis $-750 \mathrm{~km}$ - cheio de dejetos. O potencial de poluição é equivalente ao das descargas sanitárias de 30 milhões de pessoas”. Ainda, o Estado possui 
aproximadamente 220.000 propriedades rurais, sendo que, destas, 60.000 têm na suinocultura sua principal fonte de renda. Do total de 3,5 milhões de cabeças do rebanho estadual, três milhões (86\%) estão concentradas em uma área de 30.000 km², abrangendo 60 municípios no Oeste Catarinense. Assim, nessa região, a demanda bioquímica de oxigênio equivale à de uma população de 300.000.000 de habitantes" (SANTA CATARINA, 1994).

Assim, a Tabela 4 descreve o percentual de amostras de águas superficiais contaminadas por dejetos suínos em alguns municípios do Oeste Catarinense. Percebese que nos municípios de Concórdia e São Miguel d' Oeste a situação era extrema, com as amostras contaminadas em $90 \%$.

Tabela 4: Municípios, número de amostras de águas de rios, potáveis (número e percentual) e contaminadas (número e percentual).

\begin{tabular}{l|c|c|c|c|c}
\hline \multirow{2}{*}{ Município } & Número de & \multicolumn{2}{c|}{ Potáveis } & \multicolumn{2}{c}{ Contaminadas } \\
\cline { 3 - 6 } & Amostras & Número & \% & Número & \% \\
\hline São Miguel d' Oeste & 159 & 16 & 10 & 143 & 90 \\
Chapecó & 525 & 142 & 27 & 383 & 73 \\
Concórdia & 716 & 69 & 10 & 647 & 90 \\
Joaçaba & 128 & 26 & 20 & 102 & 80 \\
Videira & 137 & 16 & 12 & 121 & 88 \\
\hline
\end{tabular}

Fonte: Santa Catarina (1994).

Testa (1990, apud SILVA, 2000) relata "que 85\% das águas superficiais do Oeste Catarinense estão contaminadas, principalmente por coliformes fecais", mostrando uma grande preocupação com a qualidade das águas. Segundo dados oficiais (SANTA CATARINA, 1994), ao que parece os produtores e demais pessoas envolvidas no desenvolvimento e na expansão da suinocultura não se deram conta das consequências, em termos de volume e de potencial de poluição, dos dejetos acumulados em pequenas áreas.

Porém, ao observar que os atores envolvidos na atividade não haviam percebido a gravidade e as consequências da quantidade de dejetos, bem como o respectivo potencial de poluição e a influência sobre a quantidade e qualidade das águas, tal estudo (SANTA CATARINA, 1994) apenas constata essa preocupação e, de certa forma, deixa transparecer que os atores diretos pela produção (suinocultores) sejam os responsáveis. Marchesan adverte, no entanto, "que a temática requer uma análise maior, ou seja, o que está por trás dessa grande produção? Quem a exige? Quem 
é responsável por essa grande poluição gerada em tal atividade?" (MARCHESAN, 2007b).

Em dezembro de 2003, foi firmado o Termo de Compromisso de Ajustamento de Condutas da Suinocultura - TAC visou melhorar a qualidade ambiental em bacias hidrográficas, com enfoque no recurso "água". Implementou-se a adequação das atividades da suinocultura através da adoção de gestão tecnológica e práticas de manejo ambientalmente possíveis de aplicação em microbacias hidrográficas (TAC, 2003).

O termo foi estabelecido entre os signatários, sendo os quais, na maioria, representantes dos órgãos públicos: Ministério Público de Santa Catarina, Governo do Estado de Santa Catarina, Secretaria de Estado da Agricultura e Política Rural, Empresa de Pesquisa Agropecuária e Extensão Rural de SC - EPAGRI, Polícia Militar, Secretaria de Estado de Desenvolvimento Social, Urbano e Meio Ambiente - SDS, Fundação do Meio Ambiente - FATMA, Companhia de Polícia de Proteção Ambiental - CPPA, Associação Catarinense de Criadores de Suínos - ACCS, Sindicarne, Empresa Brasileira de Pesquisa Agropecuária - Centro Nacional de Pesquisa de Suínos e Aves EMBRAPA Suínos e Aves, e Companhia de Águas e Saneamento - CASAN.

Marchesan (2003), em pesquisas de campo, entrevistou produtores rurais, majoritariamente suinocultores do município de Concórdia, ocasião em que colheu depoimentos importantes sobre as percepções e relações dos suinocultores com os recursos naturais. Algumas dessas entrevistas explicitam a pressão econômica, social e ambiental que os produtores da época sofriam no contexto da produção agropecuária.

"Todos os rios da nossa região estão poluídos... Hoje, podemos ver, qualquer chuva que der os rios já correm sujos. Hoje, são terras que não servem pra agricultura, nem pra pastagem, apenas pra reflorestamento... Os agricultores estão cada vez mais pobres e, ao invés de progredir, estão regredindo. Os agricultores reclamam pela falta de justiça social. Hoje um colono é visto de forma preconceituosa". [No tocante a aspectos financeiros da sua produção, outro produtor reclama]: "Na época dava resultado, hoje tu não consegue se manter. Na época se trabalhava para a pessoa, hoje se trabalha para o capital, para o governo, para a indústria”.

Referente às pressões ambientais às quais estão submetidos, outro suinocultor esclarece: 
"Hoje, aqui, por exemplo, não tem mais mato. Então chegou a uma situação que a natureza não devolve mais, porque não tem. $\mathrm{Eu}$ queria que tu visse, por exemplo, a nossa fonte aqui secou e nunca tinha acontecido antes. A água sumiu (...) e, se chegar faltar água do poço artesiano, vamos buscar água aonde? No Rio Uruguai? ... E as águas sumiram".

Outra pesquisa de campo realizada pelo mesmo autor (2007) enfatizava que os suinocultores reclamavam constantemente de que não estavam sendo ouvidos e atendidos pelos poderes públicos e, principalmente, pelo capital agroindustrial. Sabiam e mostraram que o seu espaço, seu ambiente, suas paisagens, suas águas, enfim, os recursos naturais estavam sendo degradados por força da atividade econômica agropecuária, inserida no modo de produção capitalista. Além do mais, manifestavam que os ganhos referentes ao seu trabalho eram ínfimos, insuficientes e não conseguiam, muitas vezes, sequer manter as condições físicas das instalações das propriedades. Manifestavam, também, descontentamentos indicando que os problemas de saúde apresentados poderiam ser provenientes do convívio naquelas condições. E mais: reclamavam do excesso de trabalho despendido para acompanhar diuturnamente as criações; mostravam-se cansados de tanto trabalho; estavam impedidos de viajar ou participar de atividades de lazer, constatando que em tal atividade não conseguiam melhorar as condições de vida e tinham até mesmo dificuldades de oferecer aos seus filhos a escolaridade desejada.

Outra preocupação expressa pelo autor (MARCHESAN, 2007b) foi em relação à responsabilidade pelo armazenamento e destino dos dejetos. No passado, pela pequena produção de suínos e, consequentemente, o baixo volume de dejetos produzidos, havia área agricultável para o seu lançamento nas lavouras e o custo de transporte não era tão oneroso. Muitas vezes, até eram destinados a qualquer espaço disponível na propriedade ou conduzidos aos rios, que se encarregavam da "limpeza". Aliás, é bom que se diga que, por uma questão cultural e muitas vezes até por orientações dos técnicos das agroindústrias, as pocilgas eram construídas próximas aos rios. Por muito tempo, essas práticas eram consideradas "normais" para a época e, por que não dizer, até recentemente, pois a quantidade de dejetos produzidos até então era baixa comparandoa com o período posterior à modernização agropecuária, quando se introduziu a produção sistemática e em escala. 
Para armazenar a crescente quantidade de dejetos, foram construídas lagoas ou esterqueiras. Estas, muitas vezes, feitas de forma inadequada, por exemplo, muito pequenas em relação à quantidade de dejetos produzidos nas pocilgas e, com isso, sem o tempo mínimo de permanência nas esterqueiras para reduzirem o potencial de poluição. As soluções propostas e incrementadas mostraram-se relativamente satisfatórias, porém insuficientes. Além disso, coube ao suinocultor conduzir e distribuir os dejetos para as lavouras, o que implicava custos significativos, seja para armazenar, transportar e distribuir. Assim como o que os produtores recebiam pelo trabalho na atividade suinícola como resultado do seu trabalho era sempre insuficiente, inviabilizando-os de realizarem o processo adequadamente.

Por fim, enfatiza-se o aspecto fundamental desta problemática: Frente ao problema ambiental posto que, historicamente, foi constituído pela imposição de um modelo econômico, pergunta-se: quem tem de resolver o problema? Entende-se que, diante da situação criada, não é justo nem ético que o Estado e as agroindústrias se eximam de sua responsabilidade agora que o ambiente está degradado. Além do mais, não é justo, por exemplo, que as empresas agroindustriais tratem somente de resolver sua poluição industrial e não tratem da poluição decorrente de toda a cadeia de produção e, mais especificamente, na origem do processo produtivo, que ocorre junto aos seus produtores integrados.

\section{5 - CONSIDERAÇÕES FINAIS}

O estudo mostrou as causas estruturais da lógica da degradação ambiental regional, as quais estão vinculadas ao modo de produção capitalista, aos interesses do capital, da sua incessante apropriação, acumulação e influências ou interferências nas relações da sociedade humana entre si e desta sobre os bens naturais. Identificou ainda as estratégias adotadas pelo capital agroindustrial para a produção agropecuária, mediante o incentivo de agricultores que detêm certo perfil e conhecimento cultural para lidar com animais a produzirem de forma intensiva e em escala em suas propriedades. Para tanto, as agroindústrias implantaram projetos de integração como forma de incentivá-los a produzir de acordo com os interesses e expectativas das primeiras. Registrou também a evolução do sistema de produção agropecuário e suas políticas de contínuo incremento da produtividade, não levando em consideração os limites da 
natureza (no caso, mais especificamente a água) nem as condições de vida e trabalho das pessoas que atuam em tais atividades.

Verificou-se que, nas atuais condições, os suinocultores não têm poder econômico suficiente nem força ou organização política para a resolução dos problemas ambientais. De maneira geral, estão descapitalizados, desanimados com a atividade e não conseguem ter a qualidade de vida almejada devido às condições estabelecidas e ao que ganham com sua produção.

No entanto, determinados setores do próprio mercado se articulam, hoje, no sentido de punir aqueles que não têm determinados tipos de práticas conservacionistas. As empresas agroindustriais expõem seu prestígio mundial em discursos e propagandas que contêm um "marketing ambientalista", mostrando que se preocupam com as questões ambientais. Porém, a maioria delas ainda não se preocupa com as consequências de suas próprias práticas dentro de toda a sua cadeia produtiva. Essa dualidade entre teoria (discurso) e prática por parte do capital agroindustrial e do Estado demonstra claramente o jogo político dúbio frente aos problemas ambientais por eles produzidos. Nesse contexto, as empresas agroindustriais se obrigam, às vezes, a introduzir alguns elementos novos em relação ao ambiente, mesmo que apenas como marketing. Na maioria das vezes, apenas falam nas e sobre as questões, sem considerar toda a cadeia produtiva, porque não querem politizar ou socializar o lucro que elas apresentam e, assim, serem, quem sabe, desmascaradas frente ao processo ou à opinião pública. Para muitas delas, sobra a alternativa de ir para outras regiões onde ainda existe a possibilidade de operar por um tempo maior, depredando o ambiente sem a vigilância das forças que impõem uma nova relação com a natureza. Porém, cabe frisar que não é justo nem ético retirar-se do lugar quando o ambiente está, em grande parte, por tais empresas, degradado, sem deixar outras possibilidades para aquela comunidade.

Enfim, constatou-se que, em muitas áreas da região Oeste Catarinense, nem os proprietários (suinocultores), nem as agroindústrias e nem mesmo o Estado planejaram a quantidade de animais instalados por propriedade, desconsiderando o potencial de suporte dos recursos naturais, especialmente das águas superficiais.

A busca pela superação dos atuais problemas ambientais dessa Mesorregião poderá passar pela gradativa superação das atuais formas, sistemas e modelo de produção, mediante o pleno cumprimento da Legislação Ambiental, com a efetiva 
instauração de políticas públicas e privadas de recuperação e proteção dos recursos naturais.

A contribuição poderá passar, também, por uma nova dimensão política e pedagógica institucional pública ou privada a ser construída por parte de todos os envolvidos no processo produtivo. Esses sujeitos envolvidos poderão interagir, através de um processo educativo contínuo, formal ou informal, no sentido de contribuir para a superação das atuais culturas, sejam animais ou vegetais. Acredita-se na possibilidade do estímulo ao desenvolvimento de outras e novas ações, tanto para os cultivos, quanto para a criação de animais, que considerem e respeitem as condições de vida dos sujeitos e efetivem o estabelecimento de novas relações dos atores envolvidos com os recursos naturais. Eis o desafio!

\section{6 - REFERÊNCIAS}

ASSIS, F. O. Bacia Hidrográfica do rio Quilombo: Dejetos de Suínos e Impactos Ambientais. R. RAEGA, Curitiba, n.8, p. 107-122, 2004. Editora UFPR.

BELATO, Dinarte. Os camponeses integrados. Universidade Estadual de Campinas. Campinas (SP), 1985. (Dissertação de Mestrado).

BEZERRA, M. C. L.; VEIGA, J. ELI (Orgs.). Agricultura sustentável. Ministério do Meio Ambiente, dos Recursos Hídricos e da Amazônia Legal. Instituto Brasileiro do Meio Ambiente e dos Recursos Naturais Renováveis/Consórcio Museu Emílio Goeldi, Brasília, 2000.

BRASIL. Instituto Brasileiro de Geografia e Estatística (IBGE). Banco de Dados Agregados. Disponível em: 〈http:|lwww.sidra.ibge.gov.br>. Acesso em: 15/11/2010. DAGA, Jacir; CAMPOS, Alessandro T.; FEIDEN, Armin; KLOSOWSKI, Elcio S.; CÂMARA, Roberto J. Análise da adequação ambiental e manejo dos dejetos de instalações para suinocultura em propriedades na região oeste do Paraná. Eng. Agríc. V. 27, n.3. Jaboticabal. Set./Dez. 2007.

EPAGRI -/EMBRAPA. Inventário das terras e diagnóstico sócio-econômico e ambiental da sub-bacia hidrográfica Lajeado dos Fragosos. Florianópolis, 2000. ESPÍNDOLA, José Carlos. As agroindústrias no Brasil: O Caso Sadia. Chapecó: Grifos, 1999. 
GUIVANT, Júlia; MIRANDA, Cláudio Rocha (Orgs.). Desafios para o desenvolvimento sustentável da suinocultura: Uma abordagem multidisciplinar. Chapecó: Argos, 2004.

GUIVANT, Júlia. Suinocultura e Poluição no Oeste de Santa Catarina: Os desafios de implementar uma política ambiental. Raízes, Ano XVII, n. 16, março 1998.

IBGE - Instituto Brasileiro de Geografia e Estatística. @Cidades - município por município - Disponível em http://www.ibeg.gov.br. Acesso em 22/11/2010.

Disponível em http://www.ibeg.gov.br Mapas Digitais. Disponível em:-http://downloads.ibge.gov.br/downloads_geociencias.htmwww.ibge.gov.br/servidor arquivos_geo/Acesso em 25/01/2006.

JORNAL GAZETA MERCANTIL. 27-28/02, 1\%03/1999: A-8, 19.07.99: A-7 e 28.07.99: A3 e Ano LXXIX. Dossiê: Água, ouro do século XXI. São Paulo-SP.

MARCHESAN, Jairo. A questão ambiental na produção agrícola: um estudo sóciohistórico-cultural no Município de Concórdia (SC). Ijuí: Unijuí, 2003.

Homens e Natureza para o capital: o problema da água no espaço rural de Concórdia (SC). In.: SCHEIBE, Luiz Fernando; DORFMAN, Adriana (Orgs.). Ensaios a partir de "A Natureza do Espaço". Florianópolis: Fundação Boiteux, $2007 \mathrm{a}$.

A Água no contexto da suinocultura na Sub-bacia do Lajeado dos Fragosos - Concórdia (SC). Universidade Federal de Santa Catarina. (Tese de doutorado). Florianópolis, 2007b.

OLIVEIRA, P. A. V de. Manejo de água - influência do volume de dejetos produzidos. In.: Dia de campo sobre manejo e utilização de dejetos de suínos, Concórdia: Anais... Concórdia: EMBRAPA/CNPSA, 1994, p. 25-28

PILLON, C. N.; MIRANDA, C. R.; GUIDONI, A. L.; COLDEBELLA, A.; PEREIRA, R. K. Diagnóstico das propriedades suinícolas da área de abrangência do Consórcio Lambari, SC: relatório preliminar. Embrapa Suínos e Aves. Concórdia: Embrapa Suínos e Aves, 2003. 33p.

SANTA CATARINA. Manual de uso, manejo e conservação do solo. 2. Ed. Rev. Atual. e Ampl. EPAGRI. Florianópolis (SC), 1994.

SILVA, Adroaldo Pagani da. Diagnóstico Sócio, Econômico e Ambiental: Aspectos sobre a sustentabilidade da Bacia Hidrográfica dos Fragosos Concórdia/SC. 
Florianópolis: Programa de Pós-Graduação em Engenharia Ambiental da Universidade Federal de Santa Catarina, 2000.

TERMO DE COMPROMISSO DE AJUSTAMENTO DE CONDUTAS (TAC) da Suinocultura AMAUC. Disponível em:

http://www.cnpsa.embrapa.br/pnma/pdf_doc/tac.pdf., acesso em 02/11/2007. Florianópolis, 2003.

TESTA, Vilson Marcos 1. O desenvolvimento sustentável do Oeste Catarinense (Proposta para discussão). Florianópolis: Epagri, 1996. 